\title{
SUSCEPTIBILITY TO INJURY DURING FALLS IN WOMEN PRACTISING COMBAT SPORTS AND MARTIAL ARTS
}

\author{
DARIUSZ BOGUSZEWSKI ${ }^{1}$, JAKUB GRZEGORZ ADAMCZYK², KATARZYNA KERBAUM, \\ BARTŁOMIEJ ANTONIAK ${ }^{4}$, ANNA OBSZYŃSKA-LITWINIEC ${ }^{1}$, DARIUSZ BIAŁOSZEWSKI \\ Medical University of Warsaw, 2nd Medical Faculty, Department of Rehabilitation ${ }^{1}$, Student Scientific \\ Society (Division of Physiotherapy) ${ }^{3}$ \\ Józef Piłsudski University of Physical Education in Warsaw, Faculty of Physical Education, \\ Department of Sport Theory', Student Scientific Society (Division of Training Theory) ${ }^{4}$ \\ Mailing address: Dariusz Boguszewski, 2nd Medical Faculty, Department of Rehabilitation, \\ 61 Żwirki i Wigury Street, 02-091 Warsaw, tel.: +48 22 5720920, fax: +48 225720562 , \\ e-mail: dboguszewski@wum.edu.pl
}

\begin{abstract}
Introduction. Martial arts and combat sports are practical sports that are being practised by an increasing number of women. The aim of this study was to examine the relationship between the ability of female judo, taekwondo and karate competitors to fall safely and their susceptibility to injuries during falls. Material and methods. A total of 120 persons participated in the research. The study group consisted of 45 female judo, taekwondo (WTF) and karate Shotokan competitors; in the control group there were 75 persons who did not practise sport professionally. The research tools included the Test of Susceptibility to Injury during Falls (TSIDF) developed by Kalina and a questionnaire designed by the authors. Results. The female martial arts competitors had considerably lower TSIDF results $(\mathrm{p}<0.001)$, which means that they made fewer errors when performing motor tasks. The mean result of the TSIDF was 2.48 for the study group and 6.08 for the control one. Significant differences $(\mathrm{p}<0.001)$ were found between the groups for all types of errors and all of the motor tasks. Conclusions. Women practising combat sports and martial arts made significantly fewer errors in the Test of Susceptibility to Injuries During Falls, which can be seen as evidence for the practical usefulness of the training they are undergoing.
\end{abstract}

Key words: martial arts, combat sports, accidental falls, injuries, prevention, judo, taekwondo, karate, women

\section{Introduction}

Falls can occur at all ages, but children and elderly persons are the most vulnerable to them. Other groups at risk for falling are persons with disabilities, especially those with visual and locomotor deficits. Injuries resulting from falls often lead to permanent traumata, and even to death [1,2, 3]. It is estimated that among persons who are over 65 years of age about $40 \%$ are subject to falling at least once a year, and this percentage increases with age [4].

The methods of preventing falls researched so far mostly focus on the evaluation of the risk of falling, elimination of risk factors, improvement of the functioning of various organs and systems, and supplementation with calcium and vitamin D. In addition, strength and balance training is recommended as prophylaxis [5]. Although much attention is paid to activities aimed at preventing falls, seldom do researchers address the problem of preventing or minimising the harmful effects of collapsing by teaching people how to fall safely and avoid collisions. Falls cannot be completely eliminated, but the ability to protect one's body during an unexpected fall could be the most efficient method of preventing its negative consequences. Therefore, developing the habit of falling down in a safe way could help considerably diminish the severity of the resulting injuries and the number of deaths, especially in the population of elderly persons or those with disabilities $[6,7,8]$.
Preventing falls is difficult due to the complexity of their causes. Sometimes one person may have many risk factors [5, 9, 10], in which case the risk of collapsing, and sustaining injuries, is increased, and it is more difficult to establish what caused the fall. Undoubtedly, however, having a healthy lifestyle, and particularly doing physical activity, can help maintain one's independence and functional capacity. Physical activity improves posture stability and balance; it also makes it possible to increase or maintain the level of muscle strength and endurance $[11,12,13]$.

Certain traits of the ability to fall safely can be observed in several-month-old children. If they lose their balance, they most frequently sit down near their heels (the only available point of support at that moment), inclining the trunk forward, extending the hands forward and protecting the head [14]. With age, however, these habits disappear if they are not practised. Therefore exercises in falling safely could be one of elements of fall prevention programmes [7]. One technique of safe falling is ukemi, which is one of the basic elements of martial arts training, for example in judo [15, 16, 17].

The aim of the study was to compare the ability to fall safely, on the back, in women practising combat sports and martial arts (judo, taekwondo WTF and karate Shotokan) and those not practising them (both physically active and inactive women). 


\section{Material and methods}

The study involved a group of 120 women, who had been divided into two groups. Group 1 (the study group) comprised 45 female competitors who trained combat sports and martial arts. The conditions that the participants had to meet in order to be classified into the group were having a minimum of two years' training and, in addition, having a $2^{\text {nd }} \mathrm{kyu}$ in judo, $4^{\text {th }} \mathrm{kyu}$ in karate or $4^{\text {th }}$ kup in taekwondo. Group 2 (the control group) consisted of 75 persons who did not practise sport professionally (tab. 1). The participants of the study were additionally divided into subgroups. Those in group 1 were divided according to the discipline of sport trained, which were judo $(n=19)$, taekwondo $\mathrm{WTF}(\mathrm{n}=14)$ and karate Shotokan $(\mathrm{n}=12)$. Group 2 was divided based on the subjects' participation in recreational sport activities or its lack. Those who had been taking part in organised motor activities at least twice a week for a minimum of two years were classified as physically active (tab. 2).

Table 1. Characteristics of the study and control groups

\begin{tabular}{|c|c|c|c|c|}
\hline Groups & n & $\begin{array}{c}\text { Age } \\
\text { [years) }\end{array}$ & $\begin{array}{c}\text { Body mass } \\
\text { [kg] }\end{array}$ & $\begin{array}{c}\text { Body height } \\
\text { [cm] }\end{array}$ \\
\hline Group 1 (study) & 45 & $21.93 \pm 6.72$ & $56.71 \pm 7.91$ & $163.96 \pm 6.75$ \\
\hline Group 2 (control) & 75 & $22.78 \pm 2.04$ & $60.27 \pm 9.98$ & $167.39 \pm 5.35$ \\
\hline
\end{tabular}

The Test of Susceptibility to Injuries During Falls (TSIDF) designed by Kalina was used as a research tool [18]. The test consisted in performing three motor tasks. The first motor task was moving from the basic position to lying down on the back (on a mattress). In the second task, the subjects held a small sandbag pressed between the chin and the sternum while clapping their hands. In the third task, the subjects had to perform a jump before proceeding to lying down on the back. The subjects were not informed how to perform the tasks correctly. Each attempt was evaluated for errors, that is deviations from the correct model of falling safely. The results were recorded in the observation sheet. The sum of errors for particular parts of the body (the legs, hips, hands and head) collected for all three tasks served as the Test of Susceptibility to Injury During Falls Index (TSIDFI). The higher the participant's result, the greater their proneness to injuries was. According to the classification established, 0 points stands for a low level, 1 to 3 points for a medium level, 4 to 8 points for a high level, and 9 to 14 points for a very high level of susceptibility [18]. The subjects additionally filled in a specially designed questionnaire.

Standard statistical tools such as the mean and standard deviation were used. The distribution of the data was tested for normality using the Kolmogorov-Smirnov test and the differences between the data were assessed by means of Student's t-test. A value of $p<0.05$ was set as the minimum level of significance.

\section{Results}

The female combat sports and martial arts competitors had considerably lower results in the Test of Susceptibility to Injuries During Falls $(\mathrm{p}<0.001)$, which means that they committed fewer errors when performing the motor tasks. The mean TSIDF result was 2.48 for the study group and 6.08 for the control one. Statistically significant differences $(p<0.001)$ between the groups were found for all types of errors. The majority of the errors in both groups were due to an incorrect position of the upper limbs (fig. 1). Out of the three tasks which were performed in the test, the third activity, which was theoretically the most difficult one, was performed the most poorly. The fewest irregularities were observed for the second task. These tendencies were found in both groups. The differences between the groups in their performance of all of the tasks were statistically significant $(\mathrm{p}<0.001)$ (fig. 2).

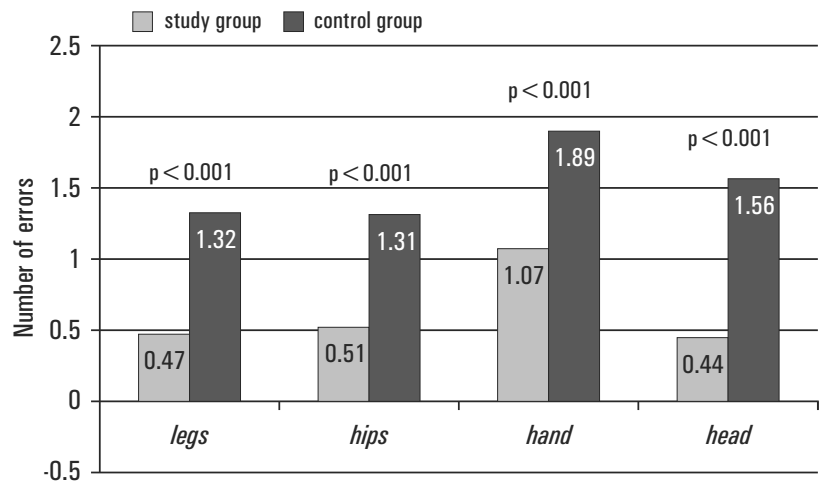

Figure 1. Results of the SIDF test for different types of errors

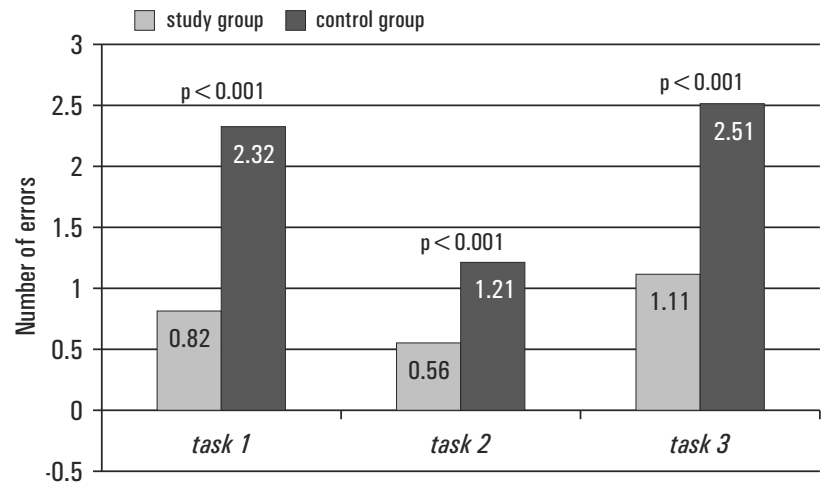

Figure 2. Results of the SIDF test

The lowest mean TSIDF result (1.47), which was characterised by the lowest number of errors, was observed in the female judokas. The female karate competitors performed slightly more

Table 2. Characteristics the study and control groups divided into subgroups

\begin{tabular}{|c|c|c|c|c|c|c|}
\hline Groups & Subgroups & $\mathbf{n}$ & Age lyears) & Body mass [kg] & Body height [cm] & Training experience [years] \\
\hline \multirow{3}{*}{ Group 1 (study) } & Judo & 19 & $20.73 \pm 5.16$ & $55.26 \pm 4.87$ & $161.74 \pm 4.88$ & $9.84 \pm 3.89$ \\
\cline { 2 - 7 } & Taekwondo & 14 & $25.42 \pm 7.44$ & $56.86 \pm 5.02$ & $164.14 \pm 5.02$ & $4.64 \pm 3.24$ \\
\cline { 2 - 7 } & Karate & 12 & $19.75 \pm 6.96$ & $58.83 \pm 8.81$ & $167.25 \pm 7.65$ & $4.68 \pm 4.74$ \\
\hline \multirow{2}{*}{ Group 2 (control) } & Active & 33 & $22.93 \pm 2.01$ & $59.71 \pm 7.28$ & $168.61 \pm 4.89$ & $4.19 \pm 3.59$ \\
\cline { 2 - 7 } & Non-active & 42 & $22.67 \pm 2.07$ & $60.7 \pm 11.74$ & $166.45 \pm 5.55$ & $\cdot$ \\
\hline
\end{tabular}


poorly (2.67) and the taekwondo competitors performed the most poorly in the study group (3.71). The difference between the results for women practising judo and those practising taekwondo was statistically significant (tab. 3). Persons from the control group (in both subgroups) committed a significantly greater number of errors than the female combat sports and martial arts competitors. Significant differences $(p<0.01)$ in the TSIDF index were also observed between the women who were physically active and inactive (tab. 3).

The female judokas made the fewest errors in each motor task in the TSIDF. The results for the tasks performed by the taekwondo and karate competitors were similar $(p>0.05)$. The women from the control group performed all the tasks in the test more poorly (tab. 4). However, fewer errors were observed in physically active persons, and the differences between the active and inactive women were statistically significant $(\mathrm{p}<0.01)$. Using the support of hands was the most frequent error in all of the subgroups. The physically inactive women committed most of their errors due to arranging the head incorrectly (1.71), and the active ones made theirs by arranging the head (1.36) and hips (1.36) in an improper way. Among the subjects who practised combat sports and martial arts the fewest errors had to do with the lower limbs (judo: 0.21; karate: 0.25 ) and the head (judo: 0.21; taekwondo: 0.43) (tab. 4).

The Test of Susceptibility to Injuries During Falls was performed flawlessly by 7 female judokas, 2 taekwondo competitors and 4 karate competitors, but not by a single woman from the control group. None of the persons practising judo and taekwondo obtained a result above 9 points, standing for very high susceptibility to injuries during falls, whereas two karate competitors and 11 persons from the control group were classified in this category. Most of the women from the control group (22 physically active and 32 inactive ones) were characterised by a high level of proneness to injuries during falls (tab. 5).

Table 3. Differences between subgroups in the SIDF test [p]

\begin{tabular}{|c|c|c|c|c|}
\hline judo & & & & \\
\hline $\mathbf{0 . 0 0 4}$ & taekwondo & & & \\
\hline 0.159 & 0.272 & karate & & \\
\hline $\mathbf{0 . 0 0 0}$ & $\mathbf{0 . 0 3 8}$ & $\mathbf{0 . 0 0 5}$ & active & \\
\hline $\mathbf{0 . 0 0 0}$ & $\mathbf{0 . 0 0 0}$ & $\mathbf{0 . 0 0 0}$ & $\mathbf{0 . 0 0 9}$ & non-active \\
\hline
\end{tabular}

Table 4. Results of the SIDF test (for the three tasks)

\begin{tabular}{|c|c|c|c|c|}
\hline & \multicolumn{4}{|c|}{ task 1} \\
\hline & & hips & hands & head \\
\hline judo & & $0.11 \pm 0.31$ & $0.37 \pm 0.76$ & $0.16 \pm 0.37$ \\
\hline taekwondo & & $0.21 \pm 0.42$ & $0.86 \pm 0.95$ & $0.36 \pm 0.49$ \\
\hline karate & & $0.08 \pm 0.28$ & $0.17 \pm 0.39$ & $0.17 \pm 0.39$ \\
\hline active & & $0.45 \pm 0.51$ & $1.15 \pm 1.01$ & $0.45 \pm 0.51$ \\
\hline \multirow[t]{3}{*}{ non-active } & & $0.45 \pm 0.50$ & $1.55 \pm 0.83$ & $0.60 \pm 0.49$ \\
\hline & \multicolumn{4}{|c|}{ task 2} \\
\hline & & hips & hands & head \\
\hline judo & & $0.05 \pm 0.23$ & $0.21 \pm 0.42$ & $0.00 \pm 0.00$ \\
\hline taekwondo & & $0.29 \pm 0.47$ & $0.36 \pm 0.74$ & $0.07 \pm 0.27$ \\
\hline karate & & $0.17 \pm 0.39$ & $0.33 \pm 0.49$ & $0.33 \pm 0.49$ \\
\hline active & & $0.45 \pm 0.51$ & $0.09 \pm 0.38$ & $0.33 \pm 0.48$ \\
\hline \multirow[t]{3}{*}{ non-active } & & $0.48 \pm 0.49$ & $0.40 \pm 0.58$ & $0.60 \pm 0.49$ \\
\hline & \multicolumn{4}{|c|}{ task 3} \\
\hline & legs & hips & hands & head \\
\hline judo & $0.21 \pm 0.63$ & $0.11 \pm 0.31$ & $0.21 \pm 0.53$ & $0.05 \pm 0.21$ \\
\hline taekwondo & $1.00 \pm 1.01$ & $0.21 \pm 0.42$ & $0.36 \pm 0.74$ & $0.00 \pm 0.00$ \\
\hline karate & $0.25 \pm 0.45$ & $0.42 \pm 0.52$ & $0.42 \pm 0.51$ & $0.33 \pm 0.49$ \\
\hline active & $1.15 \pm 1.01$ & $0.45 \pm 0.51$ & $0.15 \pm 0.37$ & $0.58 \pm 0.50$ \\
\hline \multirow[t]{3}{*}{ non-active } & $1.45 \pm 0.89$ & $0.33 \pm 0.47$ & $0.33 \pm 0.52$ & $0.52 \pm 0.51$ \\
\hline & \multicolumn{4}{|c|}{ SUM } \\
\hline & legs & hips & hands & head \\
\hline judo & $0.21 \pm 0.63$ & $0.26 \pm 0.73$ & $0.79 \pm 1.03$ & $0.21 \pm 0.42$ \\
\hline taekwondo & $1.00 \pm 1.01$ & $0.71 \pm 0.99$ & $1.57 \pm 1.34$ & $0.43 \pm 0.65$ \\
\hline karate & $0.25 \pm 0.45$ & $0.67 \pm 0.65$ & $0.92 \pm 1.16$ & $0.83 \pm 1.03$ \\
\hline active & $1.15 \pm 1.01$ & $1.36 \pm 1.08$ & $1.39 \pm 1.19$ & $1.36 \pm 0.93$ \\
\hline non-active & $1.45 \pm 0.89$ & $1.26 \pm 1.03$ & $2.29 \pm 1.19$ & $1.71 \pm 0.99$ \\
\hline
\end{tabular}

Table 5. Number of participants with low, medium, high and very high susceptibility to injury during falls

\begin{tabular}{|c|c|c|c|c|}
\hline & low & medium & high & very high \\
\hline judo & 7 & 9 & 3 & 0 \\
\hline taekwondo & 2 & 4 & 8 & 0 \\
\hline karate & 4 & 5 & 1 & 2 \\
\hline active & 0 & 9 & 22 & 2 \\
\hline non-active & 0 & 1 & 32 & 9 \\
\hline
\end{tabular}

\section{Discussion}

Since combat sports and martial arts allow for general development and include a large variety of exercises, their elements can be practised at every age, and those who do them tend to have not only a higher level of strength and endurance, but also better motor co-ordination (balance and agility), and flexibility [19, 20, 21, 22].

Posture stability (balance) is very important in the prophylaxis of falls. Bączkowicz noticed a dependence between diminished posture stability and a greater number of falls in the elderly [23]. The research by Famuła et al. and Mraz et al. confirmed the beneficial influence of the physical activity of older persons on the stability of their posture $[24,25]$. Tai Chi training in particular is highly recommended for elderly people [26, 27].

Combat sports and martial arts are often qualified as "high risk sports". They are universally considered to be dangerous for one's health because of the high rate of injuries sustained during training. However, the research conducted at the University Hos- 
pital of Groningen among persons training football, volleyball, gymnastics and combat sports showed that those training combat sports sustained injuries the least frequently [28]. Wilkerson mentions the following types of injuries as the most frequent among competitors of combat sports: minor soft tissue damage, hematomas and flesh wounds, and, more seldom, fractures (mostly of the phalanges of hands and legs) [29]. Moreover, the majority (68\%) of injuries resulted from the combat and occurred in highly qualified competitors [30, 31, 32, 33, 34, 35]. As Woodward claims, combat sports and martial arts are relatively safe in comparison to other disciplines, and most competitors sustain few injuries, particularly on the initial and intermediate levels $[36,37]$.

The results obtained in the present study show that the participants who practised combat sports and martial arts performed the motor tasks significantly better. The habit of falling safely, which is one of the basic elements of training in Far Eastern martial arts, already on the initial level of instruction, can explain these findings [15, 38, 39]. Leavitt hypothesised that learning safe falling could prevent injuries resulting from falls in a later period in life, although practising falling correctly can cause injuries as well [40]. However, according to Kalina, the techniques of learning safe falling based on judo are safe, even for the elderly; his research revealed that out of thousands of persons introduced to safe falling (based on judo criteria) only in a few cases were any injuries sustained, and not a single one by a person over 40 years old [41]. Research carried out by Weerdesteyn [42] on a group of elderly people proved that, even after a short period of training, being familiar with the techniques of falling based on martial arts reduces the risk of sustaining hip joint injuries during falls, also in persons with osteoporosis [42, 43].

Moreover, it cannot be excluded that greater physical fitness has an influence on the skill of safe falling. It was proven that the level of physical fitness could reduce the risk of the occurrence of dangerous falls [2, 26, 27, 44]. Similar observations were made in this study.

The sedentary lifestyle that tends to dominate in developed countries nowadays is not conducive to physical activity. Their citizens work mostly in a sitting position, have no time for any type of physical activity and are often obese, which makes them weaker, less physically fit and, therefore, more subject to falling. With the population ageing, the problem of falling will become increasingly pressing. That is why it is so important to devise efficient programmes for preventing falls and their harmful consequences, whose major element could be teaching people how to fall safely using techniques from martial arts training.

\section{Conclusions}

1. The female combat sports and martial arts competitors performed the motor tasks consisting in the simulation of falling backwards more effectively, which can be seen as evidence that they would be able to adapt to an unexpected fall, owing to the training they had done.

2. The fewest errors in the TSIDF were recorded for the female judokas. Judo training - already on the initial phase of instruction - includes the learning and improvement of ukemi, the model of safe falling.

3. The ability to protect oneself among the women practising combat sports and martial arts was proven particularly by the significantly lower number of errors concerning the head, the part of the body whose protection is critical during falls, made by this group in the motor tasks.

4. The results of the research conducted prove that it would be advisable to promote exercises in safe falling in different groups of people (children, adults and the elderly) as a form of preventing falls.

\section{Literature}

1. Scuffham P., Chaplin S., Legood R. (2003). Incidence and costs of unintentional falls in older people in the United Kingdom. Journal of Epidemiology and Community Health 57(9), 740-744.

2. Stevens J.A., Corso P.S., Finkelstein E.A., Miller T.R. (2006), The costs of fatal and non-fatal falls among older adults. Injury Prevention 12, 290-295.

3. Czerwiński E., Białoszewski D., Borowy P., Kumorek A., Białoszewski A. (2008). Epidemiology, clinical significance, cost and fall prevention in elderly people. Ortopedia Traumatologia Rehabilitacja 10(5), 419-428.

4. Rubenstein L.Z., Josephson K.R. (2002). The epidemiology of falls and syncope. Clinics in Geriatric Medicine. Philadelphia: W.B. Saunders Co.

5. Czerwiński E., Kumorek A., Milert A., Borowy P. (2008) Causes of falls in women in Krakow population. Ortopedia Traumatologia Rehabilitacja 10(5), 429-440.

6. Czerwiński E., Borowy P., Jasiak B. (2006). Current guidelines for using physiotherapy to prevent falls. Ortopedia Traumatologia Rehabilitacja 8(4), 380-387.

7. Kalina R.M., Barczyński B., Jagiełło W., Kruszewski A., Przeździecki B., Harasymowicz J. et al. (2008). Teaching of safe falling as the most effective element of personal injury prevention in people regardless of gender, age and type of body build - the use of advanced information technologies to monitor the effects of education. Archives of Budo 4, 82-90.

8. Gąsienica-Walczak B., Barczyński B.J., Kalina R.M., Kucio C. (2010). The effectiveness of two methods of teaching safe falls to physiotherapy students. Archives of Budo 6(2), 63-71.

9. Boguszewski D., Zabłocka M., Adamczyk J.G. (2012). Susceptibility to injury during a fall among blind children. Postępy Rehabilitacji 26(2), 63-70.

10. Boguszewski D., Zabłocka M., Adamczyk J.G., Boguszewska K., Białoszewski D. (2013). Evaluation of susceptibility to injuries resulting from falls of children with visual impairment. European Journal of Adapted Physical Activity 6(1), 716.

11. Hoornbrook M.C., Stevens V.J., Wingfield D.J., Hollis J.F., Greenlick M.R., Ory M.G. (1994). Preventing falls among community-dwelling older people. Results from randomized trial. Gerontologist 34(1), 16-23.

12. Mraz M., Mraz M., Sipko T., Anwajler J., Dąbrowska G., Skrzek A. (2006). Assessment of the influence of motor coordination on maintaining body balance in young and elderly people. Acta Bio-Optica et Informatica Medica 12(3), 145-149.

13. Famuła A., Nowotny-Czupryna O., Nowotny J., Płaszewski M. (2009). Movement activity and body stability as a part of life style in different life periods. The Journal of Orthopaedic Trauma Surgery and Related Research 3(15), 22-27.

14. Kalina R.M. (2009). Safe fall. Medical Tribune 12, 30-31.

15. Kalina R.M., Kruszewski A., Jagiełło W., Włoch G. (2003). Combat sports propaedeutics - basics of judo. Warszawa: AWF Warszawa.

16. Boguszewski D., Kerbaum K. (2011). Judo training as a means of reducing susceptibility to injury during falls. Polish Journal of Sports Medicine 27(3), 205-212.

17. Sterkowicz-Przybycień K., Oleksy M. (2013). Change in susceptibility to the body injuries observed during compulsory judo and combat sports classes among university students. The Polish Journal of the Arts and Culture 7, 171-178. [in Polish]

18 Kalina R.M., Barczyński B., Klukowski K., Langfort J., Gąsienica-Walczak B. (2011). The method to evaluate the susceptibility to injuries during the fall - validation procedure of the specific motor test. Archives of Budo 7(4), 201-215. 
19. Gierczuk D., Długołęcka B. (2009). Anaerobic capacity of lower limb muscles in juvenile wrestlers. Polish Journal of Sport and Tourism 16(2), 115-120.

20. Gierczuk D., Bujak Z. (2013). The analysis of coordination training means used in the training of wrestlers. Journal of Combat Sports and Martial Arts 4(1), 19-23.

21. Sterkowicz S., Lech G., Chwała W., Ambroży T., Jaworski J., Kłys A. (2011). Muscle strength in young judo contestants vs. untrained subjects. Archives of Budo 7(3), 179-184.

22. Sterkowicz S., Lech G., Jaworski J., Ambroży T. (2012). Coordination motor abilities of judo contestants at different age. Journal of Combat Sports and Martial Arts 3(1), 5-10.

23. Bączkowicz D., Szczegielniak J., Proszkowiec M. (2008). Relations between postural stability, gait and falls in elderly persons - preliminary report. Ortopedia Traumatologia Rehabilitacja 10(5), 476-480.

24. Mraz M., Mraz M., Sipko T., Anwajer J., Dąbrowska G., Skrzek A. (2006). Assessment of the influence of motor coordination on maintaining body balance in young and elderly people. Acta Bio-Optica et Informatica Medica 12(3), 145-149. [in Polish]

25. Famuła A., Nowotny-Czupryna O., Nowotny J., Płaszewski M. (2009). Movement activity and body stability as part of life style in different life periods. The Journal of Orthopaedic Trauma Surgery and Related Research 3(15), 22-27.

26. Metel S. (2003). The influence of Tai Chi and sensorimotor exercises on balance in the elderly. Medical Rehabilitation 7(3), 55-63.

27. Kessenich C.R. (1998). Tai Chi as a method of fall prevention in the elderly. Journal of Orthopaedic Nursing 17(4), 27-29.

28. Tenvergert E.M., Ten Duis H.J., Klasen H.J. (1992). Trends in sports injuries, 1982 1988: an in-depth study on four types of sport. The Journal of Sports Medicine and Physical Fitness 32(2), 214-20.

29. Wilkerson L.A. (1997). Martial arts injuries. The Journal of the American Osteopathic Association 97(4), 221226.

30. Pieter W. (2005). Martial arts injuries. Medicine and Sport Science 48, 59-73.

31. Green C.M., Petrou M.J., Fogarty-Hover M.L.S., Rolf C.G. (2007). Injuries among judokas during competition. Scandinavian Journal of Medicine and Science in Sports17, 205210.

32. Cynarski W.J., Kudłacz M. (2008). Injuries in martial arts and combat sports - a comparative study. Archives of Budo 4, 9197.

33. Hosseini S.G., Hosseini S. (2010). The prevalence and causes of bodily injuries in martial art kung-fu. Biomedical Human Kinetics 2, 34-37.

34. McPherson M., Pickett W. (2010). Characteristics of martial art injuries in a defined Canadian population: a descriptive epidemiological study. BMC Public Health 10:795. Retrived April 9, 2011, from PubMed database on the World Wide Web: http//www.pubmed.gov. DOI: 10.1186/1471-2458-10795 .
35. Woodward T.W. (2009). A review of the effects of martial arts practice on health. Wisconsin Medical Journal 108(1), 40-43.

36. Maffulli N., Longo U.G., Gougoulias N., Caine D.J., Denaro V. (2011). Sport injuries: a review of outcomes. British Medical Bulletin 97(1), 47-80.

37. Zetaruk M.N., Violán M.A., Zurakowski D., Micheli L.J. (2005). Injuries in martial arts: a comparison of five styles. Sports Medicine 39(1), 29-33.

38. Kalina R.M., Barczyński B. (2008). Teaching of safe falling as most effective element of personal injury prevention in people regardless of gender, age and type of body build - the use of advanced information technologies to monitor the effects of education. Archives of Budo 4, 82-90.

39. Adamczyk J.G., Antoniak B., Boguszewski D., Siewierski M. (2012). Physical fitness and safe falling skills in karate athletes. Journal of Combat Sports and Martial Arts 3(1), 53-58.

40. Leavitt F.J. (2003). Can martial arts falling techniques prevent injuries? Injury Prevention 9, 284-285.

41. Kalina A., Kalina R.M., Klukowski K. (1998). Exercises in avoiding collisions and falling safely used for rehabilitation purposes. Wychowanie Fizyczne i Zdrowotne 45(1), 20-26. [in Polish]

42. Weerdesteyn V., Groen B.E., van Swigchem R., Duysens J. (2008). Martial arts fall techniques reduce hip impact forces in naive subjects after a brief period of training. Journal of Electromyography and Kinesiology 18(2), 235-242.

43. Groen E.B., Smulders E., Duysens J., van Lankveld W., Weerdesteyn V. (2010). Could martial arts fall training be safe for persons with osteoporosis?: a feasibility study. BMC Research Notes 3:111. Retrieved April 9, 2011, from PubMed database on the World Wide Web: http//www.pubmed.gov. DOI: 10.1186/1756-0500-3-111

44. Skalska A., Walczewska J., Ocetkiewicz T. (2003). Age, gender and physical activity in persons declaring falls and the falls circumstances. Rehabilitacja Medyczna 7(3), 49-53. [in Polish]

Submitted: December 8, 2014

Accepted: January 26, 2015 